\title{
Hyperpolarization and intracellular acidification in Trichoderma viride as a response to illumination
}

\author{
MiroslaV Grešík, NadežDa Kolarova and Vladimír Farkaš* \\ Institute of Chemistry, Slovak Academy of Sciences, CS-842 38 Bratislava, Czechoslovakia
}

(Received 17 April 1991; accepted 15 July 1991)

\begin{abstract}
Using indirect methods based on uptake of $\left[{ }^{3} \mathrm{H}\right]$ tetraphenylphosphonium cation and $\left[{ }^{14} \mathrm{C}\right]$ benzoic acid by cells of the fungus Trichoderma viride we found that the illumination-induced transient hyperpolarization of the plasma membrane is followed immediately by a rapid temporary decrease in intracellular pH. Hyperpolarization and intracellular acidification were completely suppressed by $150 \mathrm{mM}-\mathrm{KCl}$ and by the $\mathrm{K}^{+}$-ionophore valinomycin. The light-induced acidification of the cytoplasm was not observed in the presence of the cytochrome respiratory chain inhibitors antimycin $A$ and mucidin. Based on these results, we hypothesize that the hyperpolarization of the cells is the consequence of an efflux of $\mathrm{K}^{+}$through a light-activated $\mathrm{K}^{+}$-channel in the plasma membrane. The loss of positive charge in the cytoplasm caused by this efflux of cations is counterbalanced by $\mathrm{H}^{+}$originating from the light-activated mitochondrial respiratory chain.
\end{abstract}

\section{Introduction}

It has become increasingly evident that movements of various ions across cellular membranes constitute an important component of the intracellular signalling pathways involved in regulation of diverse life processes, including the response of cells to various external stimuli (Krueger, 1989; Schroeder \& Hedrich, 1989).

In many fungi, e.g. Trichoderma viride, the illumination of mycelia with visible or near-UV light regulates differentiation by inducing the formation of conidia (Gressel \& Rau, 1983; Dahlberg \& Van Etten, 1982). Among the rapid biochemical changes occurring in mycelia as a response to illumination are the transient increase in membrane potential $(\Delta \psi)$ and the rise of intracellular levels of ATP and cyclic AMP (Grešík et al., 1988). The increase of the ATP concentration in mycelia could be accounted for by a rapid burst of respiratory activity induced by illumination (Sulová et al., 1990).

In the present study, using indirect methods, we investigated the relationship between the light-induced hyperpolarization of the plasma membrane and the accompanying intracellular acidification.

\footnotetext{
Abbreviations: $\Delta \psi$, plasma membrane potential; $\mathrm{TPP}^{+}$, tetraphenylphosphonium ion.
}

\section{Methods}

Organism and growth conditions. Trichoderma viride Person ex S. F. Gray, strain no. F-534 from the Czechoslovak Collection of Microorganisms (T. G. Masaryk University, Brno, Czechoslovakia), was maintained on basal medium agar slants, $\mathrm{pH} 4 \cdot 9$, containing (per litre): yeast extract, $2 \mathrm{~g} ; \mathrm{KH}_{2} \mathrm{PO}_{4}, 2 \mathrm{~g} ; \mathrm{MgSO}_{4} .7 \mathrm{H}_{2} \mathrm{O}, 2 \mathrm{~g}$; glucose, $20 \mathrm{~g}$; agar, $20 \mathrm{~g}$. Conidia from 7-d-old slant cultures were suspended in basal medium without agar and filtered through a sintered glass filter (pore size $100-200 \mu \mathrm{m})$ to remove the mycelium. The concentration of conidia was adjusted to $5 \times 10^{8} \mathrm{ml}^{-1}$ and glass microfibre filter discs (Whatman GF/A, $26 \mathrm{~mm}$ diam.) were inoculated centrally with $5 \mu \mathrm{l}$ of conidial suspension per disc and placed onto the surface of basal agar medium. Petri dishes containing the inoculated discs were wrapped in aluminium foil and incubated at $30^{\circ} \mathrm{C}$ for $36 \mathrm{~h}$.

Mycelia were photoinduced as previously described (Farkaš $e t$ al., 1985). All operations requiring darkness were done under a red safelight. The photoresponsiveness of mycelia largely depended on their age and physiological state. It is important to note that, in order to obtain a good photoresponse, the mycelium should be in immediate contact with the air (Farkaš et al., 1985). There should be no residual moisture on the surface of agar and, by visual inspection, the mycelium should be velvety and dry, with the margin of the colony reaching just to the rim of the filter disc. Mycelia younger than $32-36 \mathrm{~h}$ could not usually be photoinduced. On the other hand, mycelia that were overgrown sometimes conidiated spontaneously, starting from the centre of the colony.

Membrane potential and intracellular $p H$. The changes in plasma membrane potential $(\Delta \psi)$ and intracellular $\mathrm{pH}$ were determined by indirect methods by following the rate of uptake of $\left[{ }^{3} \mathrm{H}\right]$ tetraphenylphosphonium ion into the cells (Grešik et al., 1988) and by measuring the accumulation of [ ${ }^{14} \mathrm{C}$ ]benzoic acid in the cells, respectively (Valle $e t$ al. 1986, 1987). 
Reproducibility of results. The graphs presented show representative results chosen from at least five independent experiments. Each point is the mean value of three parallel samples; the significance of changes was evaluated by means of Student's $t$-test.

Chemicals. $\left[{ }^{3} \mathrm{H}\right] \mathrm{Tetraphenylphosphonium} \mathrm{bromide}\left(\left[{ }^{3} \mathrm{H}\right] \mathrm{TPP}^{+}\right)$, specific radioactivity $24 \mathrm{Ci} \mathrm{mmol}^{-1}\left(888 \mathrm{GBq} \mathrm{mmol}^{-1}\right)$, and $\left[{ }^{14} \mathrm{C}\right]$ benzoic acid, specific radioactivity $20 \mathrm{mCi} \mathrm{mmol}^{-1}\left(740 \mathrm{MBq} \mathrm{mmol}^{-1}\right)$ were purchased from Amersham. Valinomycin and antimycin A were from Sigma. Mucidin was kindly provided by Dr J. Subik, Food Research Institute, Bratislava, Czechoslovakia. All other chemicals used were of analytical grade.

\section{Results and Discussion}

\section{Measurement of $\Delta \psi$ and intracellular $\mathrm{pH}$}

Our previous observations (Farkaš et al., 1985; Grešík et al., 1988, 1989) have indicated that the reception of the light signal by dark-growing cells of $T$. viride is accompanied by a complex set of physiological and metabolic changes, comprising a transient increase in $\Delta \psi$ and an increase in intracellular levels of ATP and cAMP.

In the present work, we tried to explain the mechanism by which the light-induced hyperpolarization occurs. For technical reasons, it was not possible to make direct measurements of $\Delta \psi$ and/or the intracellular $\mathrm{pH}$ by means of specific micro-electrodes. Such techniques would require the illumination of hyphae during the introduction of micro-electrodes, i.e. prior to measurement itself.

As an indirect method of assessing the changes in $\Delta \psi$, we measured the rate of uptake into the cells of the lipophilic cation $\left[{ }^{3} \mathrm{H}\right] \mathrm{TPP}+$. A critical evaluation of this method was given by Eraso et al. (1984). Accordingly, the rate of $\left[{ }^{3} \mathrm{H}\right] \mathrm{TPP}{ }^{+}$uptake into the cells is proportional to $\Delta \psi$, and the constant rate of $\left[{ }^{3} \mathrm{H}\right] \mathrm{TPP}{ }^{+}$uptake reflects the stability of $\Delta \psi$. In yeast cells, and possibly also in other eukaryotic cells, uptake of $\mathrm{TPP}^{+}$takes place in two phases: the rate of TPP+ uptake during the first phase is related to $\Delta \psi$ and the second phase reflects the incorporation of TPP+ into intracytoplasmic compartments. In our experiments, the duration of the first phase was about $45 \mathrm{~min}$.

To measure changes in intracellular $\mathrm{pH}$ we used a method based on accumulation by the cells of the weak acid $\left[{ }^{14} \mathrm{C}\right]$ benzoic acid (De la Peña et al., 1982). With this method, the decrease in intracellular $\mathrm{pH}$ when the distribution of acid between the cells and medium had reached equilibrium would cause a reduction in the degree of dissociation of labelled acid in the cytoplasm and consequent diffusion of re-associated molecules of $\left[{ }^{14} \mathrm{C}\right]$ benzoic acid out of the cells (Valle et al., 1986). In our experiments, it took about $12 \mathrm{~min}$ to reach equilibrium when the cells were saturated with $\left[{ }^{14} \mathrm{C}\right]$ benzoic acid.

Owing to the fact that the cells had to be cultivated and illuminated on the surface of solid medium, it was not possible to determine the distribution of $\left[{ }^{3} \mathrm{H}\right] \mathrm{TPP}{ }^{+}$and $\left[{ }^{14} \mathrm{C}\right]$ benzoic acid between medium and the cells and to calculate the absolute values of internal $\mathrm{pH}$ and $\Delta \psi$. For this reason, the measured values should be taken only as a qualitative illustration of the changes in $\Delta \psi$ and intracellular $\mathrm{pH}$ evoked by illumination.

\section{Role of $\mathrm{K}^{+}$}

The rapid hyperpolarization of the plasma membrane immediately after the onset of illumination, observed as an abrupt increase in the rate of $\left[{ }^{3} \mathrm{H}\right] \mathrm{TPP}+$ incorporation into the cells (Fig. 1), could be explained as the result of

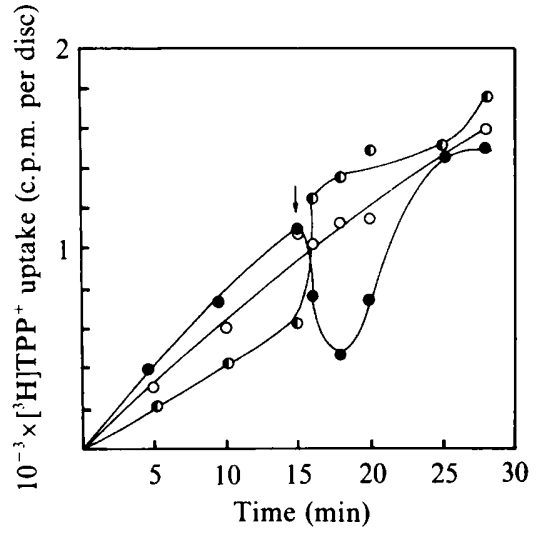

Fig. 1

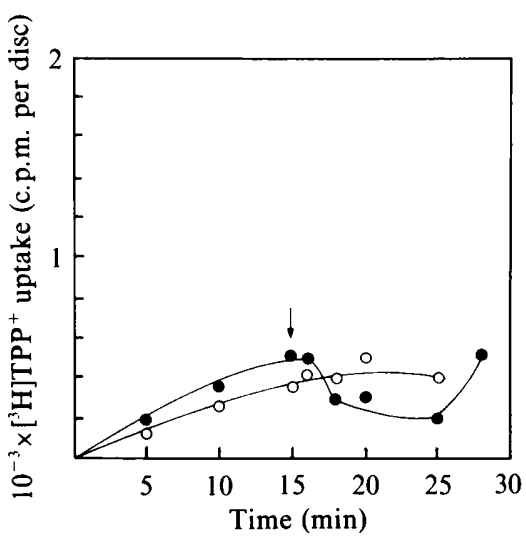

Fig. 2

Fig. 1. Effect of $\mathrm{KCl}$ on time-dependent changes of $\Delta \psi$ expressed as uptake of $\left[{ }^{3} \mathrm{H}\right] \mathrm{TPP}+$ into cells of $T$. viride. $\odot$, Illuminated control mycelium; $\bullet$, illuminated mycelium in the presence of $150 \mathrm{mM}-\mathrm{KCl} ; \mathrm{O}$, dark control. Illumination started at the time indicated by the arrow. All operations requiring darkness were done under a red safelight.

Fig. 2. Time-dependent changes in the rate of $\left[{ }^{3} \mathrm{H}\right] \mathrm{TPP}{ }^{+}$accumulation in $T$. viride in the presence of $50 \mu \mathrm{M}$-valinomycin. ๑, Illuminated mycelium; O, dark control. Other conditions were as in Fig. 1. 


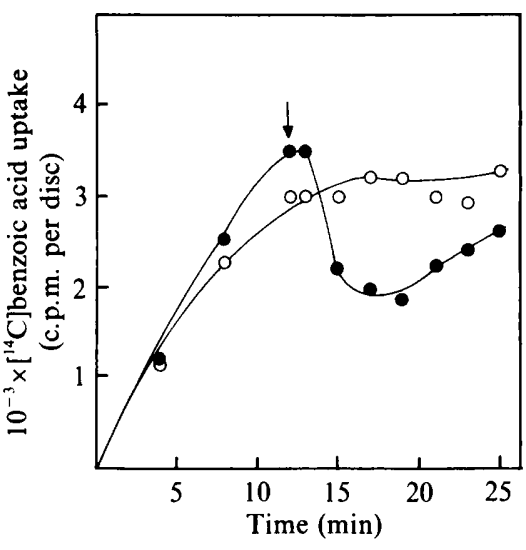

Fig. 3

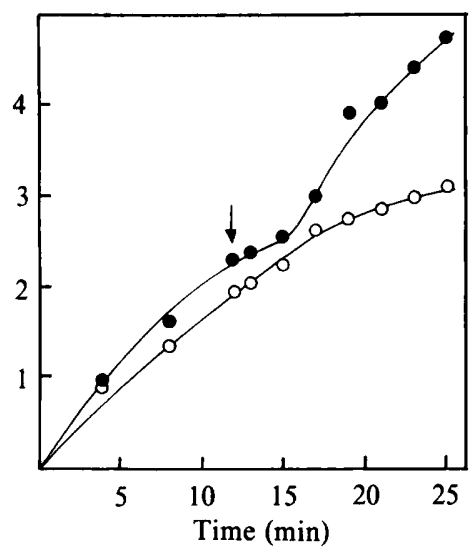

Fig. 4

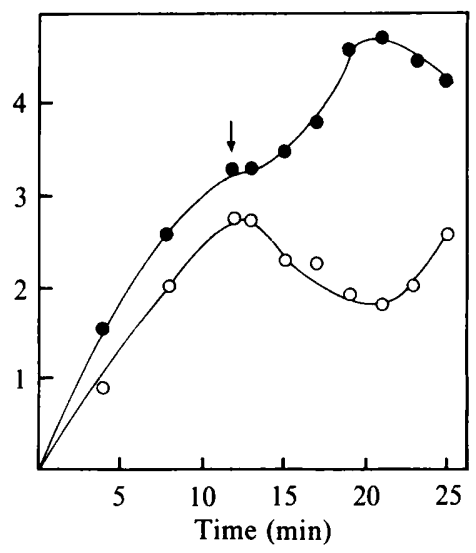

Fig. 5

Fig. 3. Time-course of $\left[{ }^{14} \mathrm{C}\right]$ benzoic acid accumulation by $T$. viride. $\bullet$, Illuminated mycelium; $\bigcirc$, dark control. Illumination started at the time indicated by the arrow.

Fig. 4. Effect of antimycin $\mathrm{A}(0)$ and mucidin $(\bullet)$ (both at $10 \mu \mathrm{g} \mathrm{ml}^{-1}$ ) on accumulation of $\left[{ }^{14} \mathrm{C}\right]$ benzoic acid by $T$. viride. Mycelia were pre-incubated with $\left[{ }^{14} \mathrm{C}\right]$ benzoic acid and the effectors for $12 \mathrm{~min}$ before illumination. Illumination started at the time indicated by the arrow.

Fig. 5. Effect of $\mathrm{KCl}(\bullet)$ and $\mathrm{NaCl}(\mathrm{O})$ (both at $150 \mathrm{mM}$ ) on accumulation of [ ${ }^{14} \mathrm{C}$ ]benzoic acid by $T$. viride. Mycelia were illuminated at the time indicated by the arrow.

an efflux of positively charged ions from the cytoplasm into the cell exterior or by a movement of negative charge from the extracellular space into the cytoplasm. The likely candidates are $\mathrm{H}^{+}, \mathrm{K}^{+}, \mathrm{Ca}^{2+}$ and/or $\mathrm{Cl}^{-}$. Since our preliminary results have shown that the $\mathrm{K}^{+}$-ionophore valinomycin was able to abolish the effect of light on $\Delta \psi$, we investigated the role of $\mathrm{K}^{+}$more closely.

The intracellular concentration of $\mathrm{K}^{+}$in fungal cells lies in the range 100-300 mM (Serrano, 1985). Fig. 1 shows that the presence of $150 \mathrm{mM}-\mathrm{KCl}$ in the medium during photoinduction not only completely prevented hyperpolarization of the plasma membrane but caused a temporary decrease in $\Delta \psi$ after illumination. Lower concentrations of $\mathrm{KCl}$, or an equimolar concentration of $\mathrm{NaCl}$ in the external medium were without effect on the hyperpolarization, and the time-course of $\left[{ }^{3} \mathrm{H}\right] \mathrm{TPP}+$ uptake during illumination in the presence of $\mathrm{NaCl}$ was the same as in the illuminated control.

This behaviour can be interpreted as follows. Illumination triggers the opening of a specific $\mathrm{K}^{+}$-channel in the plasma membrane and $\mathrm{K}^{+}$leaks out from the cells along the concentration gradient. The redistribution of $\mathrm{K}^{+}$would result in an increase in $\Delta \psi$, positive outside. However, with a sufficiently high concentration of $\mathrm{KCl}$ in the external medium, the gradient of $\mathrm{K}^{+}$would be levelled-off or reversed and the efflux of $\mathrm{K}^{+}$from the cells would be prevented (Van de Mortel et al., 1988).

An effect similar to that of external $\mathrm{K}^{+}$was observed with $50 \mu \mathrm{M}$-valinomycin present in the medium at the time of photoinduction. In the dark, valinomycin markedly lowered $\Delta \psi$, while after illumination there was a temporary decrease in $\Delta \psi$ as indicated by the loss of accumulated $\left[{ }^{3} \mathrm{H}\right] \mathrm{TPP}+$ from the cells (Fig. 2).

\section{Role of $\mathrm{H}^{+}$}

As can be seen in Fig. 1, the disturbance of $\Delta \psi$ caused by illumination was restored after about $2 \mathrm{~min}$. This may be explained by a reversal of the $\mathrm{K}^{+}$flux or by replacement of extruded cytoplasmic $\mathrm{K}^{+}$by some other cation(s). It is very probable that $\mathrm{K}^{+}$in the cytoplasm was replaced by $\mathrm{H}^{+}$. This assumption stems from the observation that approximately $2 \mathrm{~min}$ from the onset of illumination, an internal acidification took place, manifested as the loss of accumulated $\left[{ }^{14} \mathrm{C}\right]$ benzoic acid from the cells (Fig. 3).

The acidification which follows the hyperpolarization could be the result of $\mathrm{K}^{+} / \mathrm{H}^{+}$symport from the external medium, as has been described for Neurospora crassa (Takeuchi et al., 1988). Another possibility is that the $\mathrm{H}^{+}$ that caused the internal acidification were not imported from the outside, but were generated inside the cytoplasm or released into the cytoplasm from some internal compartment. In a previous report (Sulová et al., 1990) we reported that illumination of dark-grown mycelia of $T$. viride caused an oxidative burst accompanied by transfer of electrons along the cytochrome respiratory chain. Since the stimulated oxygen consumption during the oxidative burst was not accompanied by increased production of $\mathrm{CO}_{2}$ the possibility that internal acidification was due to dissociation of $\mathrm{H}_{2} \mathrm{CO}_{3}$ or of organic acids seems improbable. 
The possibility exists that $\mathrm{H}^{+}$were released into the cytoplasm by respiring mitochondria. According to the chemiosmotic theory (Mitchell, 1961), the transfer of electrons along the respiratory electron-transport chain is accompanied by translocation of $\mathrm{H}^{+}$from the mitochondrial matrix across the inner membrane into the mitochondrial intermembrane space. Since the outer mitochondrial membrane is permeable to ions and various low-molecular-mass solutes, $\mathrm{H}^{+}$that have been massively discharged from the mitochondrial matrix during the light-induced oxidative burst could reach the cytoplasm and cause a transient acidification. The massive discharge of $\mathrm{H}^{+}$from mitochondria would result in their hyperpolarization which, according to chemiosmotic theory, could be used as a driving force to generate ATP. A doubling in the intracellular level of ATP following illumination has been reported previously (Farkaš et al., 1985; Grešík et al., 1988).

In order to prove the involvement of respiration in the intracellular acidification, we examined the effect of antimycin $\mathrm{A}$ and mucidin, two inhibitors of respiration that act on the electron-transport chain. Both compounds inhibit the transfer of electrons at the level of the cytochrome $b / c_{1}$ complex, although the mechanism of their action is different (Šubík et al., 1974). Fig. 4 shows that both antimycin A $\left(10 \mu \mathrm{g} \mathrm{ml}^{-1}\right)$ and mucidin $\left(10 \mu \mathrm{g} \mathrm{ml}^{-1}\right)$ prevented the illumination-induced internal acidification.

As in the case of $\Delta \psi, 150 \mathrm{mM}-\mathrm{KCl}$ present in the medium at the time of illumination suppressed the lightinduced $\mathrm{pH}$ change (Fig. 5). On the other hand, the addition of an equimolar concentration of $\mathrm{NaCl}$ had no effect on the internal acidification.

\section{Effect of external $\mathrm{K}^{+}$on conidiation}

To confirm the physiological role of $\mathrm{K}^{+}$in the process of light-induced conidiation, we compared the effect of external $\mathrm{K}^{+}, \mathrm{Na}^{+}$and/or $\mathrm{Ca}^{2+}$ on conidiation. Mycelia that had been grown in the dark on the surface of basal medium for $36 \mathrm{~h}$ were transferred onto media supplemented with physiological concentrations of $\mathrm{KCl}$ (150 mM), $\mathrm{NaCl}(150 \mathrm{mM})$ and $/$ or $\mathrm{CaCl}_{2} \quad(25 \mathrm{mM})$ (Serrano, 1985). Controls were placed onto the basal medium without additions. After 15 min pre-incubation in the dark, the mycelia were illuminated (white fluorescent light, $2 \mathrm{klx}$ ) for $1 \mathrm{~min}$ and transferred back to the agar plates with basal medium and allowed to conidiate for $48 \mathrm{~h}$ in the dark. Photoinduction did not occur in mycelia illuminated in the presence of $150 \mathrm{mM}-\mathrm{KCl}$ whereas conidiation proceeded normally in controls and in mycelia illuminated in the presence of $150 \mathrm{~mm}-\mathrm{NaCl}$ and/or $25 \mathrm{~mm}-\mathrm{CaCl}_{2}$.

\section{Working hypothesis}

On the basis of these observations, and in accordance with our previous findings, the following working hypothesis was constructed. Illumination opens, by a so-far unknown mechanism, specific $\mathrm{K}^{+}$-channels in the plasma membrane. As a consequence, the efflux of $\mathrm{K}^{+}$ along the concentration gradient causes a hyperpolarization of the plasma membrane. The disturbed charge homeostasis in the cells resulting from the efflux of $\mathrm{K}^{+}$is compensated by $\mathrm{H}^{+}$discharged into the cytoplasm from light-activated mitochondria, thereby causing the acidification of cytoplasm. The electrochemical gradient for $\mathrm{H}^{+}$created between the inner membrane of mitochondria and the cytoplasm is used to drive the production of ATP whose intracellular concentration rapidly increases after the onset of illumination (Farkaš et al., 1985; Grešík et al., 1988).

\section{References}

Dahlberg, K. R. \& Van EtTen, J. L. (1982). Physiology and biochemistry of fungal sporulation. Annual Review of Phytopathology 20, 281-301.

De la Peña, P., Barros, F., Gascon, S., Ramos, S. \& Lazo, P. S. (1982). The electrochemical proton gradient of Saccharomyces. The role of potassium. European Journal of Biochemistry 123, 447-453.

Eraso, P., Mazon, M. J. \& Gancedo, J. M. (1984). Pitfalls in the measurement of membrane potential in yeast cells using tetraphenylphosphonium. Biochimica et Biophysica Acta 778, 516-520.

FARKAš, V., Sulová, Z. \& LehotSKÝ, J. (1985). Effect of light on the concentration of adenine nucleotides in Trichoderma viride. Journal of General Microbiology 131, 317-320.

GRESSEL, J. \& RAU, W. (1983). Photocontrol of fungal development. In Encyclopedia of Plant Physiology, vol. 16B, pp. 603-639. Edited by W. Shropshire \& H. Mohr. Berlin, Heidelberg \& New York: Springer.

GREŠík, M., Kolarova, N. \& FARKAš, V. (1988). Membrane potential, ATP and cAMP changes induced by light in Trichoderma viride. Experimental Mycology 12, 295-320.

Greš́́x, M., Kolarova, N. \& Farkaš, V. (1989). Light stimulated phosphorylation of proteins in cell-free extracts from Trichoderma viride. FEBS Letters 248, 185-187.

KRUEGER, B. K. (1989). Towards an understanding of structure and function of ion channels. Federation of American Societies for Experimental Biology Journal 3, 1906-1914.

MitchelL, P. (1961). Coupling of phosphorylation to electron and hydrogen transfer by a chemiosmotic type of mechanism. Nature, London 191, 144-148.

SCHROEDER, J. I. \& HEDRICH, R. (1989). Involvement of ion channels and active transport in osmoregulation and signalling of higher plant cells. Trends in Biochemical Sciences 14, 187-192.

SERRANO, R. (1985). Evidence for electrogenic proton pumps in fungi and plants. In: Plasma Membrane ATPase of Plants and Fungi, pp. 38-47. Boca Raton: CRC Press.

Sulová, Z., Hrmová, M. \& Farkaš, V. (1990). Photostimulated oxygen uptake in Trichoderma viride. Journal of General Microbiology 136, 2287-2290.

Šubík, J., Behứ̃, M. \& MusíleK, V. (1974). Antibiotic mucidin, a new Antimycin A-like inhibitor of electron transport in rat liver mitochondria. Biochemical and Biophysical Research Communications 57, 17-23. 
TAKeUChI, Y., SChMid, J., CAldwell, J. H. \& HaRold, F. M. (1988). Transcellular ion currents and extension of Neurospora crassa hyphae. Journal of Membrane Biology 101, 33-41.

Valle, E., Bergillos, L., Gascon, S., Parra, F. \& Ramos, S. (1986). Trehalase activation in yeast is mediated by an internal acidification. European Journal of Biochemistry 154, 247-251.
VAlle, E., Bergillos, L. \& Ramos, S. (1987). External potassium affects the internal acidification caused by addition of glucose to yeast cells. Journal of General Microbiology 133, 535-538.

VAN DE Mortel, J. B. J., Mulders, D., Korthout, H., Theuvenet, A. P. R. \& Borst-Pauwels, G. W. F. H. (1988). Transient hyperpolarization of yeast by glucose and ethanol. Biochimica et Biophysica Acta 936, 421-428. 